\title{
Future Changes in Incident Surface Solar Radiation and Contributing Factors in India in CMIP5 Climate Model Simulations
}

\author{
KImmo Ruosteenoja AND PetRI RÄISÄNEN \\ Finnish Meteorological Institute, Helsinki, Finland \\ SARVESH DEVRAJ AND SHIRISH S GARUD \\ Renewable Energy Technologies Division, Energy and Resources Institute, New Delhi, India \\ ANDERS V. LINDFORS \\ Finnish Meteorological Institute, Helsinki, Finland
}

(Manuscript received 16 January 2018, in final form 21 September 2018)

\begin{abstract}
To support the planning of future solar energy production in India, forthcoming changes in incoming surface solar radiation and the main physical factors contributing to the change were inferred from simulations performed with 27 global CMIP5 climate models. According to the multimodel-mean response, radiation diminishes by $0.5 \%-4 \%$ by the period $2030-59$ (relative to 1971-2000), in tandem with strengthening aerosol and water vapor dimming. The largest reduction is anticipated for northern India. The evolution of incident radiation in the mid- and late twenty-first century depends substantially on the emission scenario. According to the representative concentration pathways RCP2.6 and RCP4.5, solar radiation would gradually recover close to the level that prevailed in the late twentieth century. This results from the peaking of aerosol loading before midcentury while the water vapor content continuously increases somewhat. Conversely, under RCP8.5, incident radiation would still decline, although more slowly than during the early century. This coincides with a substantial increase in atmospheric water vapor content and a modest decrease in aerosol forcing. In cloud forcing, multimodel-mean changes are minor, but divergence among the model simulations is substantial. Moreover, cloud forcing proved to be the factor that correlates most strongly with intermodel differences in the solar radiation response. Multimodel-mean changes in solar radiation are small and would not crucially affect the conditions of solar energy production. Nevertheless, some individual models simulate far more substantial reductions of up to $\sim 10 \%$.
\end{abstract}

\section{Introduction}

India is a country with a high solar energy resource potential; depending on location, solar radiation received annually at the surface ranges roughly from 1700 to $2200 \mathrm{~kW} \mathrm{~h} \mathrm{~m}^{-2}$ (Mani and Rangarajan 1982; Soni et al. 2012). The incident solar radiation is typically most intense in March through May, prior to the wet and cloudy summer monsoon season (e.g., Soni et al. 2012). More than one-half of the land area of the country receives on average over $5 \mathrm{~kW} \mathrm{~h} \mathrm{~m}^{-2}$ of solar radiation per day (Ramachandra et al. 2011). Presently, energy demand is growing rapidly because of strong

\footnotetext{
Corresponding author: Kimmo Ruosteenoja, kimmo.ruosteenoja@ fmi.fi
}

economic growth, and, in order to reduce the emissions of carbon dioxide, there is a need to substitute fossil fuels by renewable energy sources. This state has led the nation to set ambitious solar energy targets for the coming years.

The National Solar Mission (NSM) of India was launched in 2010, and the initial targets of the mission were updated in 2015. The present goal is to achieve 100 gigawatt peak (GWp; i.e., nominal power) of installed grid-connected solar photovoltaic (PV) capacity by 2022 (Ministry of New and Renewable Energy 2015). These aims are backed up by various subsidies and financial assistance schemes initiated by the Ministry of New and Renewable Energy (MNRE). In recent years, the installed grid-connected PV capacity has indeed increased rapidly: figures from MNRE annual reports 
show a growth from circa $1 \mathrm{GWp}$ in 2012 to more than $13 \mathrm{GWp}$ in 2017.

During recent decades, India has experienced significant multidecadal variations in incident solar radiation; observational records indicate a decline in solar radiation (dimming) (Padma Kumari et al. 2007; Soni et al. 2012), without any clear signal of a turnaround of this trend (brightening) such as commonly seen in many other areas of the globe (Wild 2012; Soni et al. 2016; Allen et al. 2013). Allen et al. (2013) suggest that the dimming signal over India is predominantly caused by increasing aerosol loading. With these recent changes in the incident solar radiation in mind, together with the foreseen strong growth in installed solar energy capacity, it is of utmost importance to investigate the future evolution of solar radiation conditions induced by anthropogenic climate change.

Previously, projections of surface solar radiation change for multiple regions of the world have been derived from CMIP3 climate models by Ruosteenoja and Räisänen (2013; Europe and northern Atlantic Ocean), Anandhi et al. (2014; Malaprabha River basin in India), Delgado et al. (2014; western Brazil), and Saenz and Huang (2015; North America). Correspondingly, global-scale projections calculated from the most recent (CMIP5) ensemble of models have been published by Wild et al. (2015). In addition, they examined in more detail multiple focal regions, one of them being northwestern India $\left(20^{\circ}-30^{\circ} \mathrm{N}, 70^{\circ}-80^{\circ} \mathrm{E}\right)$.

Downwelling solar radiation is fundamentally constrained by solar geometry that remains unchanged under changing climate. The portion of the radiative flux that reaches the surface is determined on the one hand by the atmospheric gases that absorb shortwave radiation [the most important of which is water vapor; the secondmost important gas absorbing shortwave radiation is ozone, but its contribution to absorption is globally only about one-third of that of water vapor (Chou 1990) and is even smaller in low latitudes where the ozone column is thin]; on the other hand, radiation is attenuated by absorption and scattering by aerosol particles and cloud droplets and ice crystals. These absorbing and scattering agents are subject to changes under changing climate, potentially influencing the rate of incoming solar radiation at the surface.

The purpose of the present work is to assess how downwelling surface solar radiation in India might change in the future and whether the changes are prominent enough to affect the conditions of solar energy production. Silicon photovoltaic cells utilize wavelengths approximately between 400 and $1100 \mathrm{~nm}$ (Meydbray et al. 2012) that encompass the bulk of the solar spectrum [roughly two-thirds of the incoming solar radiation at the top of the atmosphere (Gueymard 2004) and even more at the surface]. Moreover, to obtain insight into the physical background of the projected changes, we explore modeled changes in the main climatological factors that affect incident radiation: aerosol loading, atmospheric humidity content, and cloud radiative forcing. All analyses are founded on simulations performed with a wide ensemble of global climate models (GCMs) participating in CMIP5 (Taylor et al. 2012). Both multimodel-mean changes and intermodel differences are considered.

Relative to the recent analyses (e.g., Wild et al. 2015), the present work contains several extensions. First, the analysis of future projections is supported by evaluation of modeled solar radiation data for recent past conditions against observational data (section 2). Second, the projections extend to the end of the century and, in addition to the high-emission scenario, are given for two greenhouse gas emission mitigation scenarios (sections $3 \mathrm{a}$ and $3 \mathrm{~b}$ ). Third, the projections are elaborated on a seasonal level rather than focusing on the annual means alone. Fourth, the dependence of the surface solar radiation response on projected changes in water vapor content, aerosol burden and cloud attenuation ratio is explored model by model (section 3c). In addition to presenting the geographical distribution, the projections are examined in more detail for two focal locations representing southern and northern India. Focusing on pointwise changes rather than spatial means can be justified by the fact that solar power production is dependent on conditions specifically at the site of the plant.

\section{Model data: Description and validation}

\section{a. Climate models}

The 27 GCMs utilized in the present study are listed in Table 1. Since the focus of the analysis is on long-term mean climatological changes rather than on daily variability, model output represented at the monthly-mean level is used to calculate monthly, seasonal, and annual 30 -yr running means. In selecting the models, the key criterion was the availability of data for the various climate quantities. Moreover, to avoid giving excessive weight to individual modeling centers, we include at most two model versions per center. Typically, model versions developed by the same center tend to yield more similar results than the different GCMs in general, both for future projections and the simulations of current climate (Leduc et al. 2016). Still, in some cases even models originating from the same institute have marked differences; for example, in MIROC5 spatial resolution is twice that in MIROC-ESM. When three or more model versions from the same center were available in the CMIP5 
TABLE 1. GCMs used in creating the projections. The first and second columns state the model acronym (expansions are available at https://www.ametsoc.org/PubsAcronymList) and the country of origin. Columns 3-5 indicate the availability of model data for the three RCP scenarios. Correspondingly, the last four columns show the variables for which data are provided by the models. The column labels are defined in section 2 a.

\begin{tabular}{|c|c|c|c|c|c|c|c|c|}
\hline Model & Country & $\mathrm{RCP} 2.6$ & RCP4.5 & RCP8.5 & RSDS & RSDSCS & PRW & OD550AER \\
\hline MIROC5 & Japan & $\mathrm{X}$ & $\mathrm{X}$ & $\mathrm{X}$ & $\mathrm{X}$ & $\mathrm{X}$ & $\mathrm{X}$ & $\mathrm{X}$ \\
\hline MIROC-ESM & Japan & $\mathrm{X}$ & $\mathrm{X}$ & $\mathrm{X}$ & $\mathrm{X}$ & $\mathrm{X}$ & $\mathrm{X}$ & $\mathrm{X}$ \\
\hline MRI-CGCM3 & Japan & $\mathrm{X}$ & $\mathrm{X}$ & $\mathrm{X}$ & $\mathrm{X}$ & $\mathrm{X}$ & $\mathrm{X}$ & $\mathrm{X}$ \\
\hline FGOALS-g2 & China & $\mathrm{X}$ & $\mathrm{X}$ & $\mathrm{X}$ & $\mathrm{X}$ & $\mathrm{X}$ & $\mathrm{X}$ & \\
\hline INM-CM4.0 & Russia & & $\mathrm{X}$ & $\mathrm{X}$ & $\mathrm{X}$ & $\mathrm{X}$ & $\mathrm{X}$ & \\
\hline NorESM1-M & Norway & $\mathrm{X}$ & $\mathrm{X}$ & $\mathrm{X}$ & $\mathrm{X}$ & $\mathrm{X}$ & $\mathrm{X}$ & $\mathrm{X}$ \\
\hline NorESM1-ME & Norway & $\mathrm{X}$ & $\mathrm{X}$ & $\mathrm{X}$ & $\mathrm{X}$ & $\mathrm{X}$ & $\mathrm{X}$ & $\mathrm{X}$ \\
\hline HadGEM2-ES & United Kingdom & $\mathrm{X}$ & $\mathrm{X}$ & $\mathrm{X}$ & $\mathrm{X}$ & $\mathrm{X}$ & $\mathrm{X}$ & $\mathrm{X}$ \\
\hline HadGEM2-CC & United Kingdom & & $\mathrm{X}$ & $\mathrm{X}$ & $\mathrm{X}$ & $\mathrm{X}$ & $\mathrm{X}$ & $\mathrm{X}$ \\
\hline MPI-ESM-LR & Germany & $\mathrm{X}$ & $\mathrm{X}$ & $\mathrm{X}$ & $\mathrm{X}$ & $\mathrm{X}$ & $\mathrm{X}$ & \\
\hline MPI-ESM-MR & Germany & $\mathrm{X}$ & $\mathrm{X}$ & $\mathrm{X}$ & $\mathrm{X}$ & $\mathrm{X}$ & $\mathrm{X}$ & \\
\hline CNRM-CM5 & France & $\mathrm{X}$ & $\mathrm{X}$ & $\mathrm{X}$ & $\mathrm{X}$ & $\mathrm{X}$ & $\mathrm{X}$ & \\
\hline IPSL-CM5A-LR & France & $\mathrm{X}$ & $X$ & $\mathrm{X}$ & $\mathrm{X}$ & $X$ & $\mathrm{X}$ & $\mathrm{X}$ \\
\hline IPSL-CM5A-MR & France & $\mathrm{X}$ & $\mathrm{X}$ & $\mathrm{X}$ & $\mathrm{X}$ & $\mathrm{X}$ & $\mathrm{X}$ & $\mathrm{X}$ \\
\hline $\mathrm{CMCC}-\mathrm{CM}$ & Italy & & $\mathrm{X}$ & $\mathrm{X}$ & $\mathrm{X}$ & & $\mathrm{X}$ & \\
\hline CMCC-CMS & Italy & & $\mathrm{X}$ & $\mathrm{X}$ & $\mathrm{X}$ & & $\mathrm{X}$ & \\
\hline GFDL-CM3 & United States & $\mathrm{X}$ & $X$ & $\mathrm{X}$ & $\mathrm{X}$ & $\mathrm{X}$ & $\mathrm{X}$ & $\mathrm{X}$ \\
\hline GFDL-ESM2M & United States & $\mathrm{X}$ & $\mathrm{X}$ & $\mathrm{X}$ & $\mathrm{X}$ & $\mathrm{X}$ & $\mathrm{X}$ & $\mathrm{X}$ \\
\hline GISS-E2-R & United States & $\mathrm{X}$ & $\mathrm{X}$ & $\mathrm{X}$ & $\mathrm{X}$ & $\mathrm{X}$ & $\mathrm{X}$ & \\
\hline GISS-E2-H & United States & $\mathrm{X}$ & $\mathrm{X}$ & $\mathrm{X}$ & $\mathrm{X}$ & $\mathrm{X}$ & $\mathrm{X}$ & \\
\hline NCAR CCSM4 & United States & $\mathrm{X}$ & $\mathrm{X}$ & $\mathrm{X}$ & $\mathrm{X}$ & $\mathrm{X}$ & $\mathrm{X}$ & \\
\hline NCAR CESM1 (CAM5) & United States & $\mathrm{X}$ & $\mathrm{X}$ & $\mathrm{X}$ & $\mathrm{X}$ & $\mathrm{X}$ & $\mathrm{X}$ & $\mathrm{X}$ \\
\hline CanESM2 & Canada & $\mathrm{X}$ & $\mathrm{X}$ & $\mathrm{X}$ & $\mathrm{X}$ & $\mathrm{X}$ & $\mathrm{X}$ & \\
\hline ACCESS1.0 & Australia & & $\mathrm{X}$ & $\mathrm{X}$ & $\mathrm{X}$ & $\mathrm{X}$ & $\mathrm{X}$ & $\mathrm{X}$ \\
\hline ACCESS1.3 & Australia & & $\mathrm{X}$ & $\mathrm{X}$ & $\mathrm{X}$ & $\mathrm{X}$ & $\mathrm{X}$ & $\mathrm{X}$ \\
\hline CSIRO Mk3.6.0 & Australia & $\mathrm{X}$ & $\mathrm{X}$ & $\mathrm{X}$ & $\mathrm{X}$ & $\mathrm{X}$ & $\mathrm{X}$ & $\mathrm{X}$ \\
\hline EC-EARTH & Europe & $\mathrm{X}$ & $\mathrm{X}$ & $\mathrm{X}$ & $\mathrm{X}$ & & $\mathrm{X}$ & \\
\hline
\end{tabular}

archive, we selected those two versions that are most different from one another; for example, the two MIROC-ESM versions (unlike MIROC5) use an identical submodel for the atmosphere (Flato et al. 2013, their Table 9.A.1).

The present database is somewhat narrower than that exploited by Wild et al. (2015), but the number of research centers covered is nearly the same. For some models, several parallel runs have been performed; these use the same greenhouse gas forcing but slightly different initial conditions (Collins et al. 2013, p. 1039). In the present work, however, we studied only one parallel run per model.

The principal variable for which the projections were calculated was incident solar radiation at the surface, also termed all-sky global horizontal irradiance; in the CMIP5 data archive, the official acronym of this variable is "RSDS." The other variables analyzed were clear-sky solar radiation (i.e., solar radiation at the surface in a hypothetical situation in which the sky is permanently free of clouds; the acronym is "RSDSCS"), vertically integrated atmospheric water vapor content (also termed precipitable water or total column water vapor; the acronym is "PRW"), and aerosol optical depth at the 550-nm wavelength (the acronym "OD550AER"). In the CMIP5 archive, aerosol optical depth has been specifically given for this wavelength that is close to the spectral maximum of solar radiation. Data for incident solar radiation and water vapor were available from all of the 27 GCMs. Clear-sky radiation data were provided by 24 GCMs and aerosol optical depth by 15 GCMs only (Table 1).

Besides the variables directly available in the CMIP5 archive, we examined the cloud attenuation ratio calculated by

$$
\text { CLD_ATTEN }=(\text { RSDSCS }- \text { RSDS }) / \text { RSDSCS } .
$$

CLD_ATTEN is used as a measure for the influence of cloud forcing on surface solar radiation. Variables needed to calculate analogous attenuation ratios for atmospheric water vapor and aerosols are not given in the CMIP5 archive. Therefore, the future trends of the vapor content and aerosol optical depth were analyzed as such.

Future projections were calculated for three representative concentration pathway scenarios: RCP2.6, 
corresponding to small emissions; RCP4.5, corresponding to moderate emissions; and RCP8.5, corresponding to large emissions (van Vuuren et al. 2011). For RCP4.5 and RCP8.5, output data are provided by all 27 GCMs (Table 1), whereas simulations under RCP2.6 have been performed by only 21 GCMs. Accordingly, in the present work RCP2.6 projections will be given less emphasis than the projections under the two other RCP scenarios.

The original model data were represented on the native grid of each individual GCM. To calculate the multimodel statistics, the data were interpolated bilinearly onto a common $2.5^{\circ} \times 2.5^{\circ}$ grid. Projected changes in all variables have been calculated relative to the mean of the reference period 1971-2000. When studying changes in a limited area like India, a 30-yr averaging period is more robust to the influence of stochastic interannual variations than, for example, the 20-yr period used by the Intergovernmental Panel on Climate Change (IPCC) in examining global-scale changes (Collins et al. 2013). It is also in accordance with the recommendations of WMO (1989) to calculate climatological standard normals.

In deriving the multimodel means and uncertainty estimates for the projections, we first calculated the changes simulated by the individual GCMs in absolute terms and fitted a Gaussian distribution to this manifold to find the median and the $5 \%-95 \%$ uncertainty interval for the projected change. Last, the 5th, 50th, and 95th percentiles of the distribution were transformed into percent through normalization by the multimodel mean of the parameter value for the reference period.

In calculating the multimodel statistics, all 27 GCMs were given an equal weight. Thus, we did not attempt to optimize the model weights depending on how well they simulate the present-day solar radiation climate in India, for instance. Nonequal weighting would be warranted only if there were unambiguous information about the performance of individual models in simulating future climate (Weigel et al. 2010). Moreover, it will be demonstrated in section $3 \mathrm{~d}$ that the future projections of solar radiation are almost unrelated to the ability of the GCMs to simulate present-day conditions. Recall, however, that many models use similar parameterization methods, and the present collection of GCMs should therefore not be regarded as a random sample of mutually independent models (Flato et al. 2013, p. 755).

\section{b. Validation of model data}

The model output files were first checked for the technical fitness of the data. The data for both solar radiation quantities and atmospheric water vapor content were found to be free of physically unreasonable values. Aerosol optical depth manifested fairly large intermodel differences, which presumably reflect the divergent algorithms used in the parameterization of aerosol physics in the various models. It should be noted that although the CMIP5 models generally use the same aerosol emission inventories based on the selected RCP, some models apply prescribed (offline) aerosol information while others use prognostic aerosol schemes, enabling a coupling between aerosol physics and meteorological conditions (Allen et al. 2013). Moreover, the GISSE2-R, GISS-E2-H, and CSIRO Mk3.6.0 GCMs employ black carbon and organic carbon emissions that are stronger than the general CMIP5 standard (Allen et al. 2013). More detailed information about the models and especially about the parameterization of aerosol processes is given in section 9 of the Fifth Assessment Report of IPCC [Flato et al. (2013), in particular, see Table 9.A.1 and references given therein].

The quality of the modeled radiation data was further validated by comparing the multimodel-mean all-sky and clear-sky downwelling solar radiation at the surface for the years 2001-15 with corresponding observational estimates. These estimates were extracted from the Clouds and the Earth's Radiant Energy System (CERES) Energy Balanced and Filled (EBAF) surface product, version 2.8 (Kato et al. 2013). This dataset has been derived through radiative transfer modeling using input data (cloud properties, aerosol optical depth, concentrations of absorbing gases and surface albedo) mainly from satellite observations and atmospheric reanalyses (for details, see Kato et al. 2013). These input data have been objectively adjusted in order to make the computed topof-the-atmosphere radiation consistent with the CERES EBAF satellite measurements (Loeb et al. 2009).

Considering the mean of the $27 \mathrm{GCM}$ simulations for this 15 -yr period, apart from the arid regions in northwestern India surface solar radiation is most abundant, about $300 \mathrm{~W} \mathrm{~m}^{-2}$, in the premonsoon season from March to May (Fig. 1). In June-August, the months of the summer monsoon season, the simulated solar radiation in wide areas of the Indian peninsula and the Bengal area barely exceeds $200 \mathrm{~W} \mathrm{~m}^{-2}$. Similar amounts of radiation are received in northern India in winter. Considering the spatial resolution of the GCM data, this spatiotemporal distribution is in a fairly good qualitative agreement with the observational estimates (Fig. 1). Nonetheless, over the Indian subcontinent modeled radiation mostly exceeds its observational counterpart by $0-30 \mathrm{~W} \mathrm{~m}^{-2}$. During the monsoon season, the overestimation is somewhat larger, reaching up to 40 $50 \mathrm{~W} \mathrm{~m}^{-2}$ in northern India. The tendency of GCMs to overestimate surface radiation in land areas is apparent even globally (Bartók et al. 2017, and references therein). Simulations of the time-mean incident radiation 

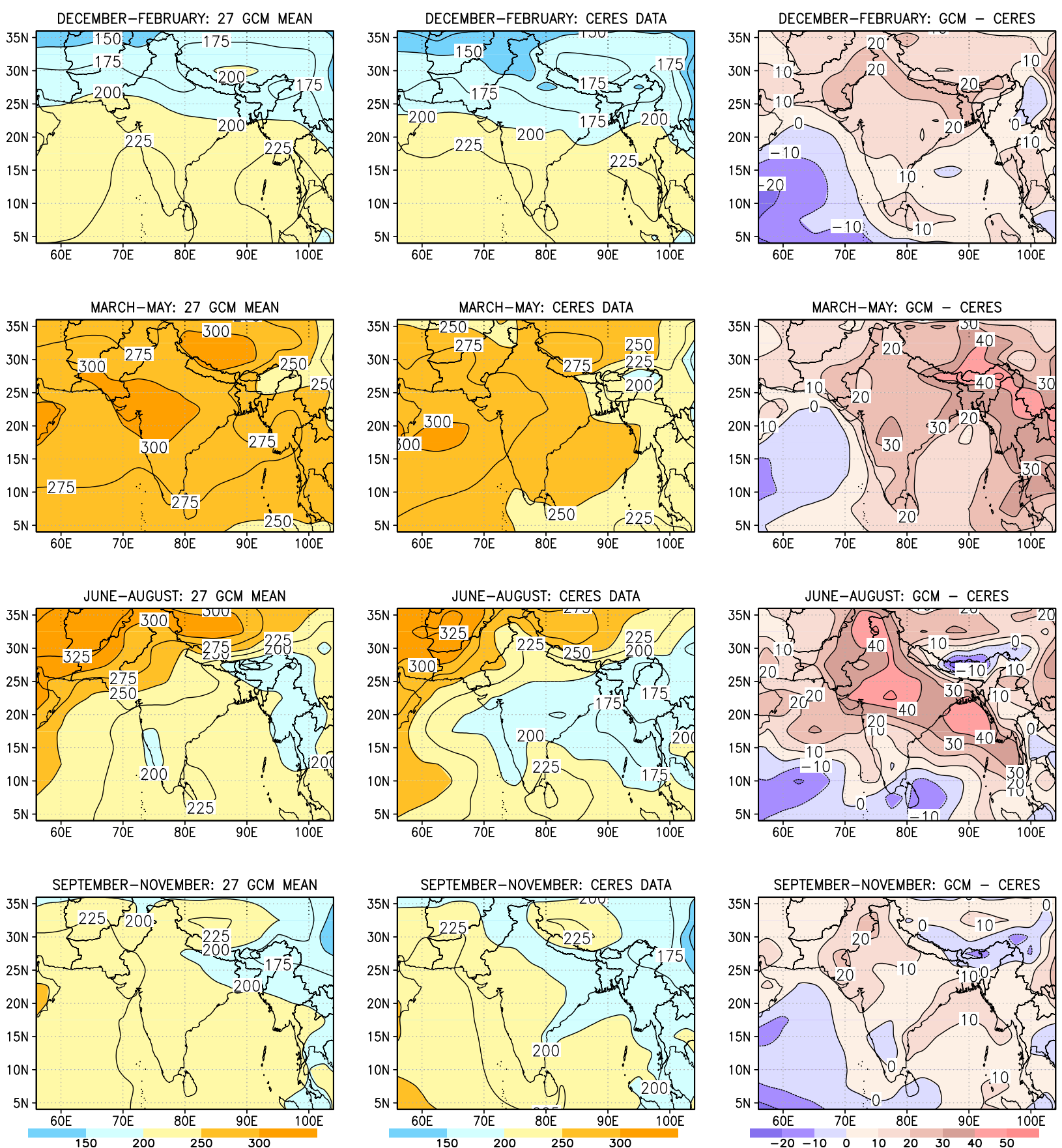

FIG. 1. Seasonal means of incident surface solar radiation $\left(\mathrm{W} \mathrm{m}^{-2}\right)$ in India and the surrounding areas averaged over the period of 2001-15: (left) an average over the simulations of 27 GCMs, (center) the observational estimate derived from the CERES data, and (right) the difference between the fields. The comparison is presented separately for (top) December-February, (top middle) March-May, (bottom middle) June-August, and (bottom) September-November.

by the individual GCMs in conjunction with projected changes will be examined in section $3 \mathrm{~d}$.

Biases in the incident all-sky solar radiation partly stem from a widespread oversimulation of clear-sky radiation by $10-30 \mathrm{~W} \mathrm{~m}^{-2}$ (not shown). In addition, in summer there was a noteworthy bias in cloud forcing. In
July-August, the cloud attenuation ratio [Eq. (1)] derived from the GCM simulations averaged $\sim 0.2-0.4$, with the exception of arid regions in northwestern India. Relative to the corresponding estimate calculated from the CERES data, the multimodel mean underestimated the ratio by $0.05-0.1$, apart from the southern Indian 
peninsula. Conversely, in the other seasons model simulations of the ratio agreed with observations moderately well, and the errors were mainly well below 0.05 . During the dry winter and premonsoon seasons, both the simulated and observational cloud attenuation ratios were generally close to 0.1 ; that is, clouds reduce the incident solar radiation by about $10 \%$.

The satellite records used here are too short to reveal any robust trends in radiation quantities. In Allen et al. (2013), the trends of solar radiation derived from a large ensemble of CMIP5 GCMs were compared with surface measurements. For India, they uncovered a significant underestimation in the modeled dimming trend over the period 1971 to 2007: in the multiGCM average, the simulated trend in all-sky radiation was $-1.5 \mathrm{~W} \mathrm{~m}^{-2} \mathrm{decade}^{-1}$, while the corresponding observational trend was about $-7.5 \mathrm{Wm}^{-2} \mathrm{decade}^{-1}$. In addition to an eventual general underestimation of emissions over India, Allen et al. (2013) suggest that this discrepancy might be explained by model biases in absorption due to black carbon.

For the atmospheric column water vapor content, the comparison data were extracted from the ERA-Interim reanalyses (Dee et al. 2011). In a qualitative sense, the seasonal cycle of water vapor content agreed between the multimodel-mean simulation and the reanalysis, but the models showed a tendency to underestimate the column water vapor to some degree. The discrepancy was largest in northern India in summer, locally more than $10 \mathrm{~kg} \mathrm{~m}^{-2}$.

The modeled aerosol optical depth averaged over the years $2000-08$ exceeded 0.5 in northern India in summer. This is comparable to the corresponding observational estimate derived from the Multiangle Imaging SpectroRadiometer (MISR) satellite data by Dey and Di Girolamo (2010). In winter, the simulated optical depths were close to or smaller than 0.2 everywhere in India, which is a severe underestimation compared with the MISR data. No detailed quantitative comparison has been made owing to possible sampling-related biases in the MISR data. For example, rainy and cloudy periods with decreased aerosol loading due to washout by precipitation may be underrepresented in the data; for additional caveats, see Dey and Di Girolamo (2010). In any case, it is likely that the underestimation of both water vapor and aerosol radiative forcing partially explains the above-discussed positive biases in modeled incident solar radiation.

\section{Results}

\section{a. Future changes in incident radiation}

Projected changes in incident surface solar radiation are depicted in Fig. 2 (spatial distribution) and Fig. 3

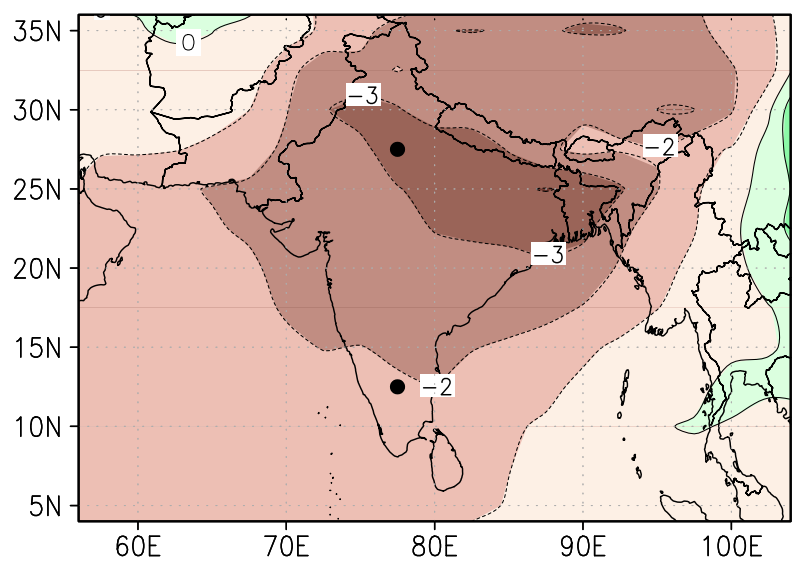

FIG. 2. Projected changes in annual total incident solar radiation at the surface (\%) in India and its adjacent areas from 1971-2000 to 2030-59 under RCP8.5: an average over 27 GCMs. The positions of the two grid points $\left(12.5^{\circ} \mathrm{N}, 77.5^{\circ} \mathrm{E}\right.$ and $\left.27.5^{\circ} \mathrm{N}, 77.5^{\circ} \mathrm{E}\right)$ that are examined in the more detailed analyses are marked by dots.

(temporal evolution). Time series are given for two locations, one situated near Delhi in northern India within the area of the most intense solar radiation decline and the other in southern India close to Bangalore. In addition to the multimodel means, the $5 \%-95 \%$ probability intervals for the change are shown. Seasonal differences will be discussed later in this section and in section $3 c$.

In the first few decades of the ongoing century, the multimodel-mean response to all three RCP scenarios manifests a decline of surface solar radiation by $\sim 1 \%-$ $3 \%$. After that, the responses to the three forcing scenarios gradually diverge. According to RCP8.5, a slow decline continues until the late twenty-first century, while in the responses to the other two scenarios, solar radiation tends to recover close to the baseline level by the end of the century. As will be discussed in section 4 , the reasons for the qualitatively different temporal evolution in the various scenarios are most likely related to differing changes in water vapor and aerosols. The temporal evolution is qualitatively similar in both target areas. In quantitative terms, the decrease is strongest in northern and northeastern India in the densely populated areas surrounding the Ganges valley. Under the two other scenarios as well, northern India is the area with largest reductions in solar radiation, but the responses are consistently far weaker than those under RCP8.5 (Fig. 3).

Nonetheless, intermodel spread in the solar radiation response is fairly large (Fig. 3, bottom panels). At the northern Indian grid point, the sign of the change is nearly certain only under RCP 8.5 , with the probability of a negative change higher than $95 \%$. Under the other two scenarios, a negative response is likewise much 

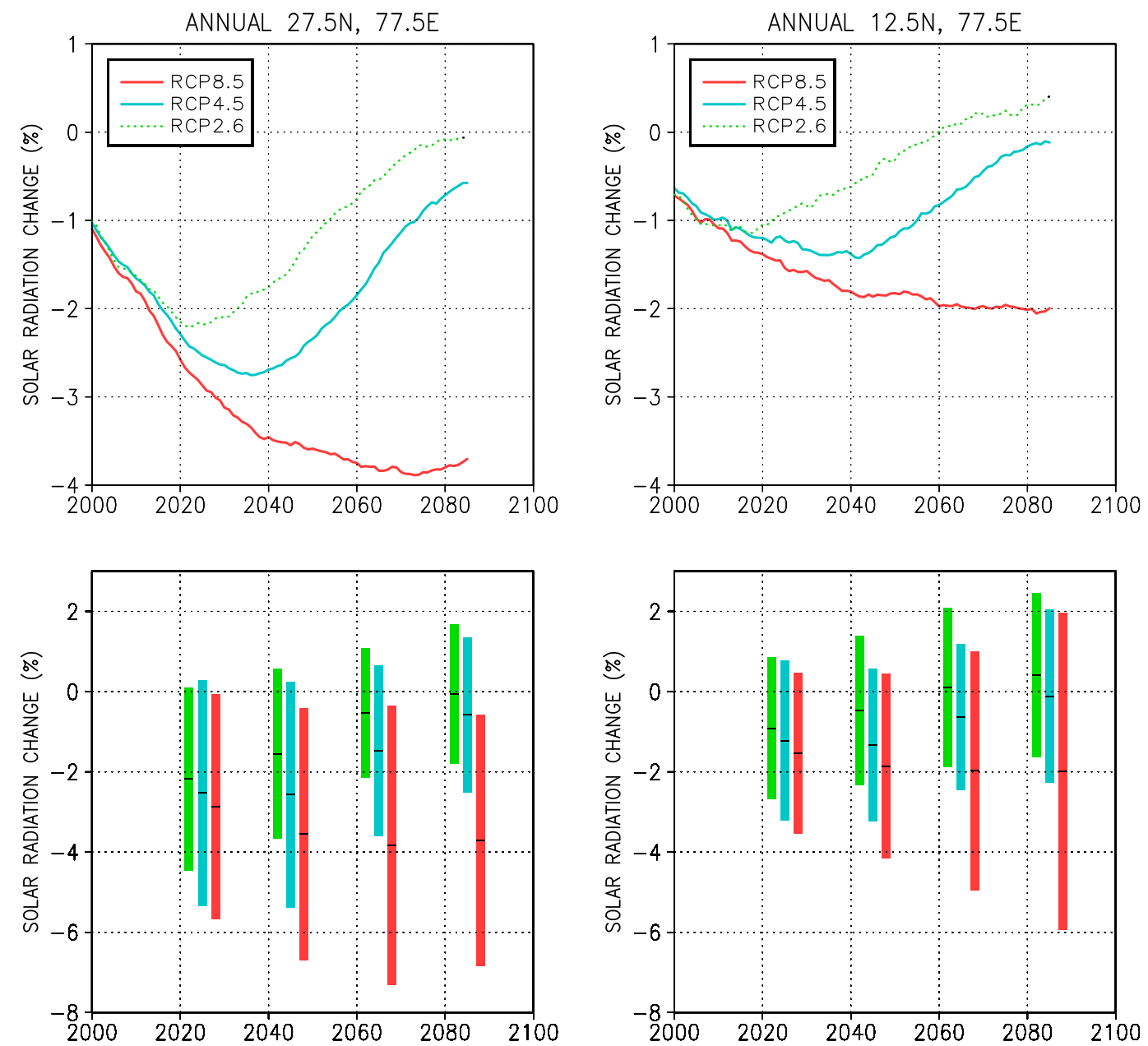

FIG. 3. (top) Projected 30-yr running multimodel-mean changes in annual total incident solar radiation at the surface (\%) at two locations $\left(27.5^{\circ} \mathrm{N}, 77.5^{\circ} \mathrm{E}\right.$ and $12.5^{\circ} \mathrm{N}, 77.5^{\circ} \mathrm{E}$; the positions are marked in Fig. 2) for 2000-85, relative to the mean of the baseline period 1971-2000. Projections are averages over 21 GCMs for RCP2.6 and 27 GCMs for RCP4.5 and RCP8.5 (see the legend). (bottom) 5\%-95\% uncertainty intervals of the change for four $30-y r$ periods centered around 2025, 2045, 2065, and 2085, separately for the three RCP scenarios.

more likely than a positive one during the early and midcentury, but in the late twenty-first century, the sign of change cannot be established. At the southern point, the response is less robust than in the north.

The uncertainty intervals calculated for the various RCP scenarios tend to overlap to a substantial degree (Fig. 3, bottom panels). Even so, in the second half of the century, surface solar radiation simulated for the RCP2.6 (RCP4.5) scenario exceeds that for RCP8.5 in all 21 GCMs (25 GCMs out of 27) examined. In the late twenty-first century, the annual-mean response to RCP8.5 is positive in one GCM and close to zero in another one, while the remaining models simulate negative changes of varying strength.

Besides the amplitude of the response, the timing of the maximum negative response diverges among the models. Even so, when exploring the response to RCP4.5 at the northern target point as an example, in 18 GCMs out of 27 the minimum value falls between the years 2030 and 2049. In three GCMs, the minimum occurs before 2030 and in one of them after 2050, while five GCMs do not produce any distinct temporal minimum.

The seasonal course and intermodel differences in the solar radiation response are displayed in Fig. 4 (monthly responses under RCP8.5) and Table 2 (seasonal changes under RCP4.5 and RCP8.5). We focus on the midcentury period 2030-59, during which the response to RCP4.5 is still strong and, on the other hand, the change under RCP8.5 has reached nearly its full intensity. For convenience, the year has been divided into four three-month seasons. The DecemberFebruary season is dry at both example locations 

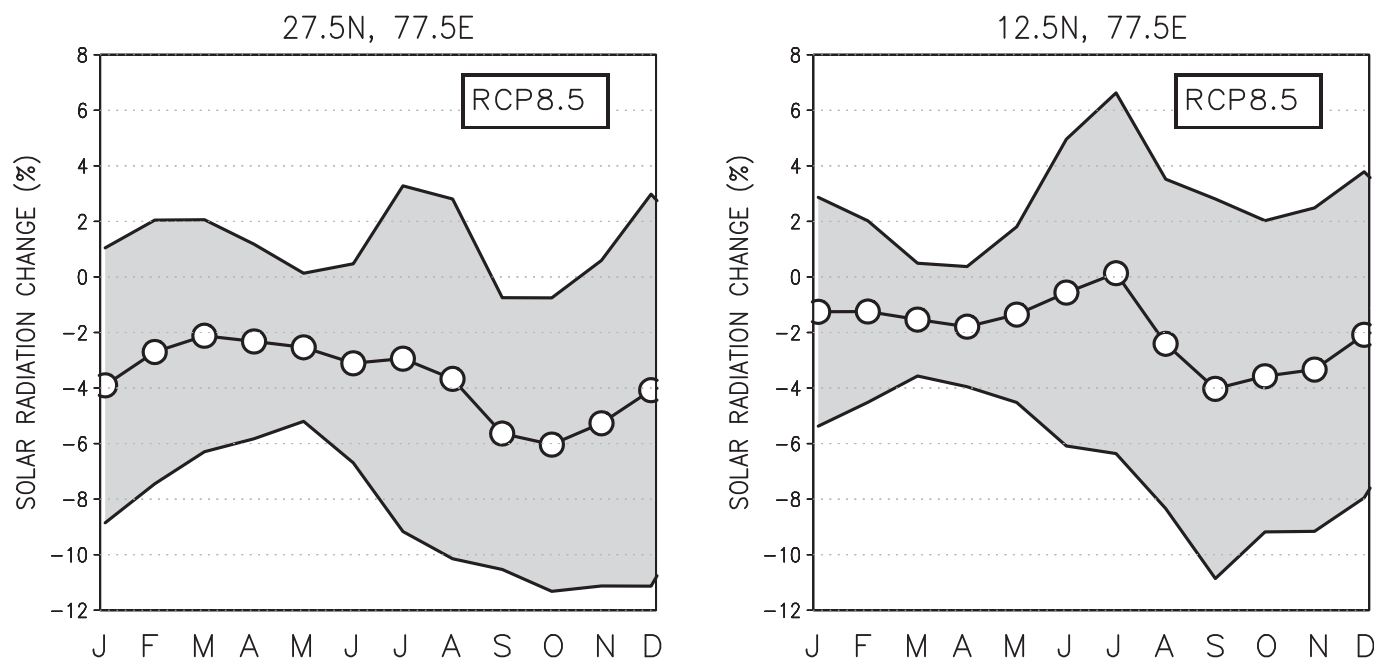

FIG. 4. Projected changes in incident surface solar radiation (\%) at (left) $27.5^{\circ} \mathrm{N}, 77.5^{\circ} \mathrm{E}$ and (right) $12.5^{\circ} \mathrm{N}, 77.5^{\circ} \mathrm{E}$ under RCP8.5 for the period of 2030-59, relative to 1971-2000. The multimodel-mean projections for individual calendar months (first $\mathbf{J}=$ January, ..., D = December) are denoted by open circles. Shading shows the $90 \%$ uncertainty intervals for the projection.

(Lockwood 1974), while June-August constitutes the rainy monsoon season. The premonsoon season from March to May is very dry in the north, but in the south rains have already commenced. In September-November, the rainy season ends in the north but in the south this season is the wettest one (Lockwood 1974). A nearly identical definition of the seasons has been applied, for example, in Dey and Di Girolamo (2010), with the exception that in their work September was included in the monsoon season.

Considering the average of the $27 \mathrm{GCMs}$, surface solar radiation is projected to decrease to some degree in all seasons, but the most intense reduction takes place in the postmonsoon season from September to November. In this season, the multimodel-mean decline is $4 \%-6 \%$ in the northern and about $3 \%$ in the southern example location. In the north in September-October, even the upper end of the $5 \%-95 \%$ probability interval resides below the line of zero change, that is, the probability of diminishing solar radiation exceeds $95 \%$. In these months, the lower end of the probability interval corresponds to a decline of about $10 \%$. In the other seasons, the projected reduction is more modest and, correspondingly, the model agreement on the sign of change is weaker. The RCP8.5 scenario consistently yields somewhat larger responses than RCP4.5.

\section{b. Changes in climate quantities accounting for the radiation response}

Projected changes in clear-sky surface solar radiation, water vapor content of the atmospheric column, aerosol optical depth and cloud attenuation ratio at the two example grid points are shown in Fig. 5 (time series for multimodel annual means) and Table 2 (seasonal changes with uncertainty estimates). Recall that water vapor content is the only variable of these with data available from all GCMs; projections for the other variables have been derived from a smaller set of GCMs (Table 1).

The projected temporal evolution of the clear-sky (Figs. 5a,e) and all-sky solar radiation (Fig. 3) is very similar. In addition to the annual averages, this holds true for the seasonal means (not shown). It is evident that the multimodel-mean response of both radiation quantities is largely determined by the same forcing factors, that is, changes in attenuation by water vapor and aerosol particles, while changes in cloudiness play a secondary role. Even so, intermodel variations are weaker for the clear-sky radiation projections, particularly in the south.

In the vertically integrated atmospheric water vapor content (Figs. 5b,f), nearly all model projections agree on an increasing future trend. In general, no drastic changes are anticipated to occur in relative humidity, and therefore vapor content in the atmosphere tends to follow simulated changes in temperature in accordance with the Clausius-Clapeyron relationship (Lorenz and DeWeaver 2007).

The evolution of aerosol optical depth (Figs. $5 \mathrm{c}, \mathrm{g}$ ) is nonmonotonic. During the first decades of this century, the aerosol concentrations increase, but, depending on the RCP scenario examined, the trend peaks and turns downward around 2020-50. Under RCP8.5, the multimodel-mean concentration exceeds the baselineperiod level even in the late twenty-first century. In 
TABLE 2. Projected seasonal changes in all-sky and clear-sky incident solar radiation at the surface, atmospheric water vapor content, aerosol optical depth at $550 \mathrm{~nm}$ (all in percent), and cloud attenuation ratio (in percentage points) for the period 2030-59 (relative to 1971$2000)$ at two locations in India $\left(27.5^{\circ} \mathrm{N}, 77.5^{\circ} \mathrm{E}\right.$ and $\left.12.5^{\circ} \mathrm{N}, 77.5^{\circ} \mathrm{E}\right)$ under RCP4.5 and RCP8.5. The multimodel-mean change is given first, followed by the $90 \%$ uncertainty interval in parentheses.

\begin{tabular}{|c|c|c|c|c|}
\hline Variable & Dec-Feb & Mar-May & Jun-Aug & Sep-Nov \\
\hline & & RCP4.5: $27.5^{\circ} \mathrm{N}, 77.5^{\circ} \mathrm{E}$ & & \\
\hline Solar radiation & $-2.2($ from -5.8 to 1.5$)$ & -1.6 (from -4.1 to 0.8$)$ & -2.5 (from -6.7 to 1.6$)$ & $-4.2($ from -8.5 to 0.1$)$ \\
\hline Clear-sky radiation & $-2.9($ from -6.2 to 0.4$)$ & -1.8 (from -3.8 to 0.3$)$ & -2.1 (from -5.0 to 0.8$)$ & -3.6 (from -7.0 to -0.2$)$ \\
\hline Water vapor content & $11.6(0.5-22.8)$ & $12.0(0.1-23.9)$ & $12.3(4.4-20.3)$ & $17.1(6.1-28.1)$ \\
\hline Aerosol optical depth & 74 (from -85 to 234$)$ & $21($ from -17 to 60$)$ & $12($ from -22 to 47$)$ & $62($ from -14 to 138$)$ \\
\hline \multirow[t]{2}{*}{ Cloud attenuation ratio } & -0.3 (from -2.3 to 1.6$)$ & 0.1 (from -1.5 to 1.6$)$ & $0.5($ from -2.4 to 3.5$)$ & $0.5($ from -1.7 to 2.7$)$ \\
\hline & & RCP4.5: $12.5^{\circ} \mathrm{N}, 77$. & & \\
\hline Solar radiation & $-0.9($ from -3.3 to 1.5$)$ & $-1.0($ from -3.0 to 1.0$)$ & $-1.0($ from -5.0 to 2.9$)$ & $-2.5($ from -6.4 to 1.3$)$ \\
\hline Clear-sky radiation & $-1.2($ from -2.1 to -0.3$)$ & $-1.4($ from -2.6 to -0.3$)$ & -0.7 (from -1.8 to 0.4$)$ & -1.6 (from -3.0 to -0.2$)$ \\
\hline Water vapor content & $9.7(0.6-18.7)$ & $11.1(6.7-15.4)$ & $10.8(5.7-15.9)$ & $12.2(5.2-19.2)$ \\
\hline Aerosol optical depth & $36(9-63)$ & $28(1-55)$ & $4($ from -28 to 36$)$ & $45(3-88)$ \\
\hline \multirow[t]{2}{*}{ Cloud attenuation ratio } & -0.4 (from -2.0 to 1.3$)$ & -0.3 (from -1.6 to 0.9$)$ & -0.1 (from -2.1 to 2.0$)$ & $0.4($ from -1.9 to 2.7$)$ \\
\hline & & RCP8.5: $27.5^{\circ} \mathrm{N}, 77.5^{\circ} \mathrm{E}$ & & \\
\hline Solar radiation & -3.5 (from -8.0 to 1.0$)$ & $-2.3($ from -5.4 to 0.7$)$ & -3.2 (from -7.6 to 1.2$)$ & -5.7 (from -9.9 to -1.5$)$ \\
\hline Clear-sky radiation & -3.8 (from -7.8 to 0.2$)$ & -2.3 (from -4.8 to 0.2$)$ & $-2.8($ from -6.0 to 0.4$)$ & -4.6 (from -8.8 to -0.5$)$ \\
\hline Water vapor content & $16.5(5.1-27.8)$ & $16.1(2.0-30.1)$ & $15.3(7.5-23.1)$ & $22.7(10.9-34.5)$ \\
\hline Aerosol optical depth & $105($ from -90 to 301$)$ & $33($ from -18 to 84$)$ & 20 (from -18 to 59$)$ & $88($ from -13 to 189$)$ \\
\hline \multirow[t]{2}{*}{ Cloud attenuation ratio } & 0.2 (from -1.9 to 2.2 ) & $0.2($ from -1.5 to 2.0$)$ & $0.6($ from -2.6 to 3.7$)$ & $1.0($ from -1.4 to 3.4$)$ \\
\hline & & RCP8.5: $12.5^{\circ} \mathrm{N}, 77.5^{\circ} \mathrm{E}$ & & \\
\hline Solar radiation & $-1.5($ from -5.0 to 2.0$)$ & $-1.6($ from -3.6 to 0.5$)$ & -0.9 (from -5.0 to 3.2$)$ & $-3.6($ from -7.7 to 0.4$)$ \\
\hline Clear-sky radiation & $-1.7($ from -3.2 to -0.3$)$ & $-2.2($ from -3.6 to -0.7$)$ & $-1.3($ from -2.5 to 0.0$)$ & $-2.2($ from -4.1 to -0.4$)$ \\
\hline Water vapor content & $12.7(3.3-22.1)$ & $13.6(8.1-19.2)$ & $13.6(7.8-19.4)$ & $15.9(8.6-23.2)$ \\
\hline Aerosol optical depth & $58(16-101)$ & $55(18-92)$ & $20($ from -16 to 56$)$ & $68(7-129)$ \\
\hline Cloud attenuation ratio & -0.3 (from -2.9 to 2.2 ) & -0.5 (from -2.0 to 0.9$)$ & -0.4 (from -3.0 to 2.2$)$ & $0.8($ from -1.5 to 3.1$)$ \\
\hline
\end{tabular}

contrast, the other RCP scenarios exhibit weaker aerosol forcing after about 2060 than during the reference period. However, it is important to note that the projections for aerosol optical depth are prone to a very large intermodel spread. In the northern example location in winter, the uncertainty interval derived from the RCP8.5 simulations ranges from nearly a total disappearance of aerosol forcing to a threefold increase (Table 2). Potential causes behind the intermodel differences in simulated aerosol burden were discussed in section 2 .

In the multimodel-mean projection, future changes in cloud attenuation ratio are mainly very minor, a few tenths of a percentage point (Figs. 5d,h). These trends are small compared to the interannual variability of the annualmean cloud attenuation ratio derived from the CERES EBAF data. For the northern and southern target points, the temporal standard deviation of that quantity was found to be 1.3 and 1.4 percentage points, respectively. This finding is in accordance with Collins et al. (2013) and Wild et al. (2015) who reported negligible future change in annual-mean cloud fraction over the Indian area. Nevertheless, this conclusion is not valid for the individual models since, compared to the multimodel mean, the intermodel spread in the changes of cloud attenuation ratio is substantial (Table 2). This topic will be discussed more comprehensively in the next section (section 3c).

During September-November, cloud attenuation is seen to increase slightly even in the multimodel mean. Correspondingly, in that season the rise of atmospheric water vapor content is consistently larger than in the other seasons. The modeled increasingly humid and cloudy future conditions in autumn are in agreement with the anticipated delay of the monsoon retreat (Christensen et al. 2013, p. 1226).

\section{c. Dependencies among the modeled changes in the different climate quantities}

To gain a deeper insight into the physical mechanisms inducing changes in incident surface solar radiation, we next examine relationships between changes in incident radiation and the variables contributing to these changes within the model ensemble. It is the absolute rather than relative changes in the forcing agents that account for the future changes in the incident all-sky radiation at the surface. Accordingly, we focus here on the intermodel dependencies of absolute changes in the various climate quantities. The dependencies are illustrated in Figs. 6 
(A) CLEAR-SKY RADIATION 27.5N, 77.5E

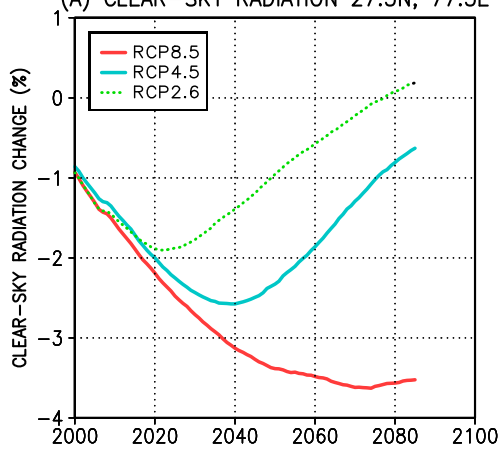

(B) WATER VAPOUR CONTENT $27.5 \mathrm{~N}, 77.5 \mathrm{E}$
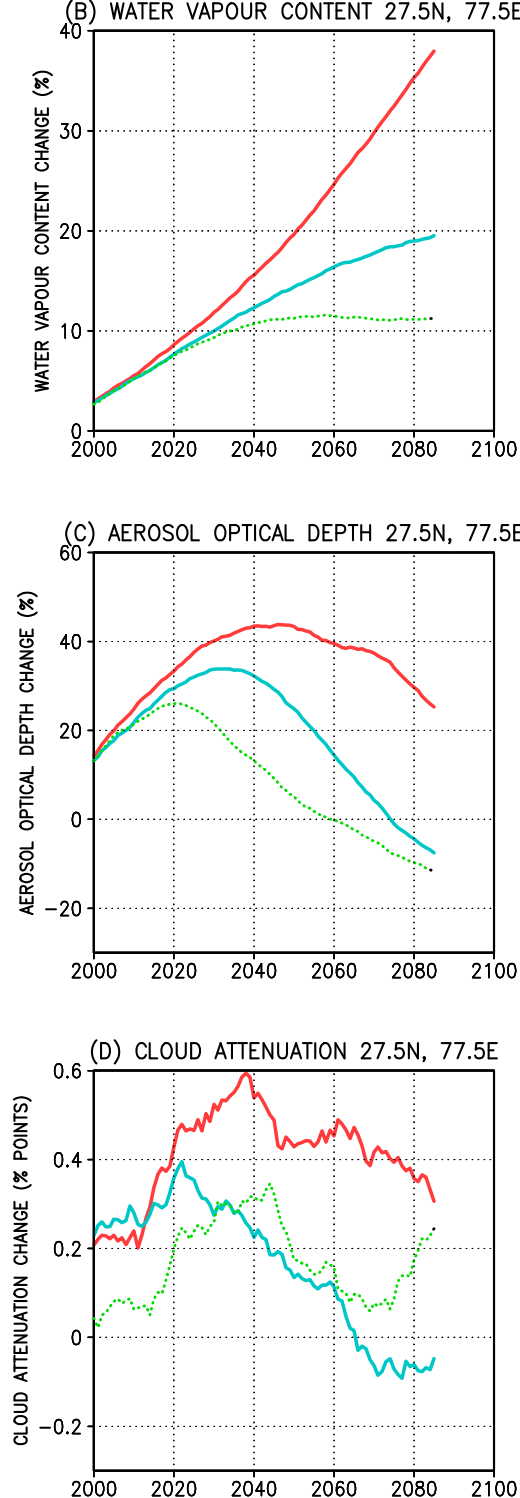

(E) CLEAR-SKY RADIATION 12.5N, 77.5E
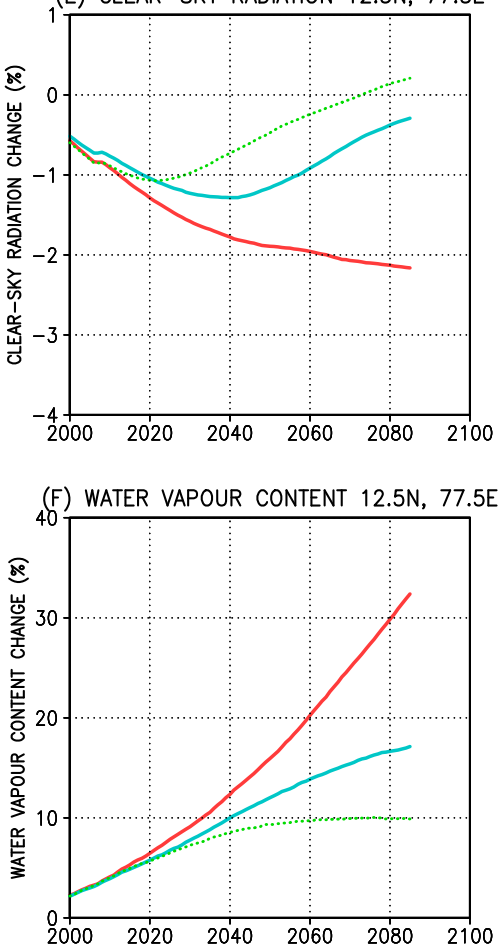

(G) AEROSOL OPTICAL DEPTH $12.5 \mathrm{~N}, 77.5 \mathrm{E}$
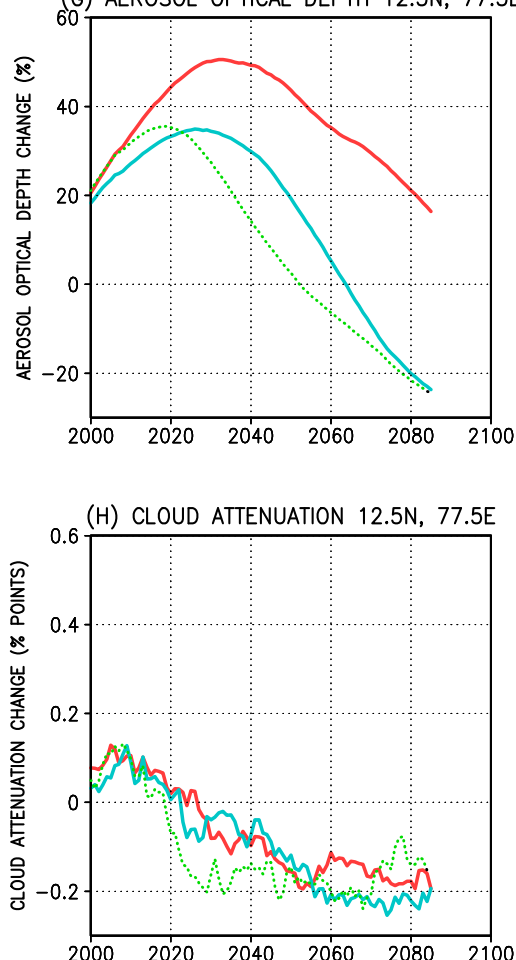

FIG. 5. Projected multimodel-mean annual changes in (a),(e) clear-sky incident solar radiation at the surface, (b),(f) atmospheric water vapor content, (c),(g) aerosol optical depth at $550 \mathrm{~nm}(\%)$, and (d),(h) cloud attenuation ratio (in percentage points) at (left) $27.5^{\circ} \mathrm{N}, 77.5^{\circ} \mathrm{E}$ and (right) $12.5^{\circ} \mathrm{N}, 77.5^{\circ} \mathrm{E}$. For further information, see the legend of Fig. 3 . 
27.5N, 77.5E, DEC-FEB 2030-2059

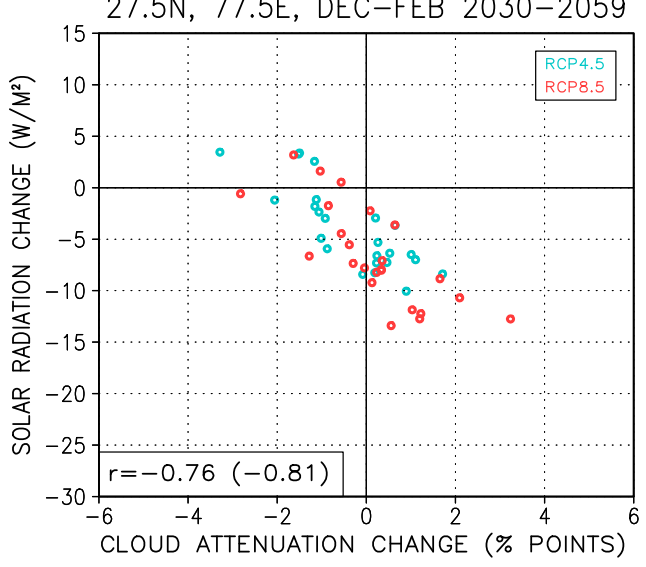

27.5N, 77.5E, DEC-FEB, 2030-2059

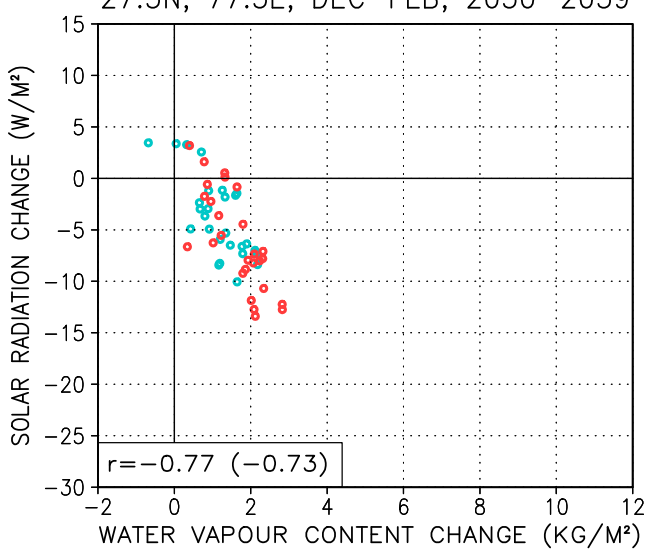

27.5N, 77.5E, DEC-FEB 2030-2059

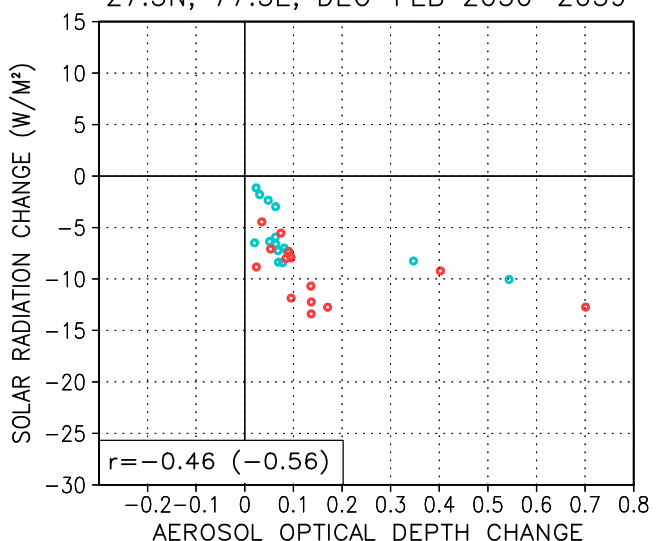

$27.5 \mathrm{~N}, 77.5 \mathrm{E}$, JUN-AUG, 2030-2059
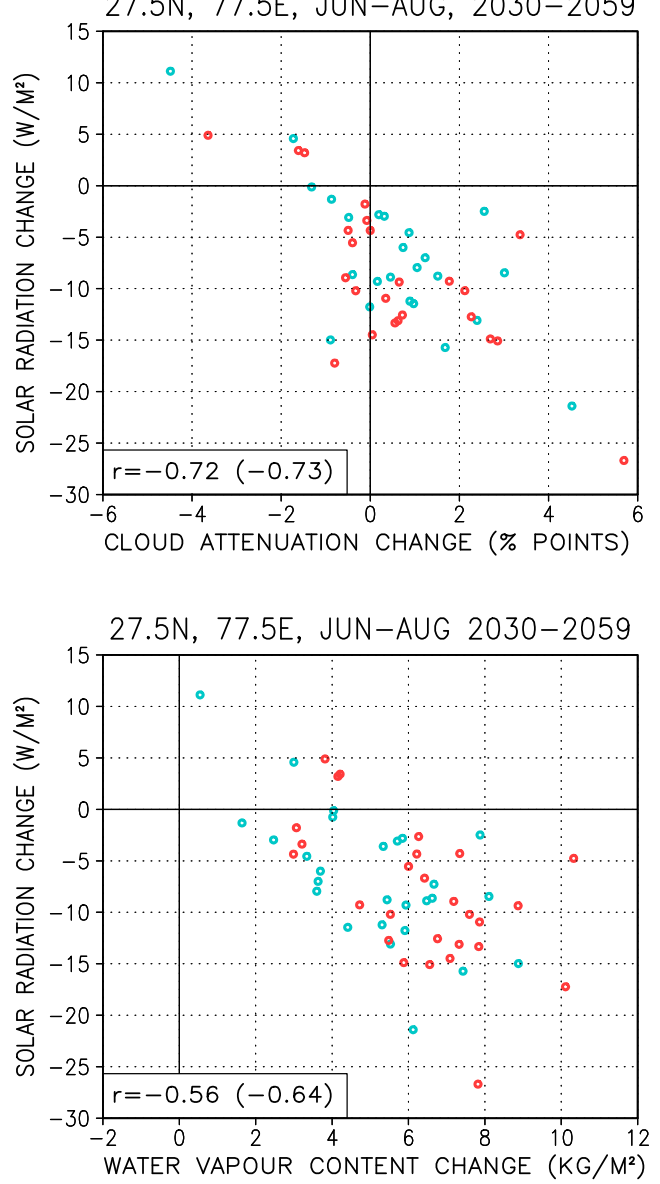

$27.5 \mathrm{~N}, 77.5 \mathrm{E}$, JUN-AUG, 2030-2059

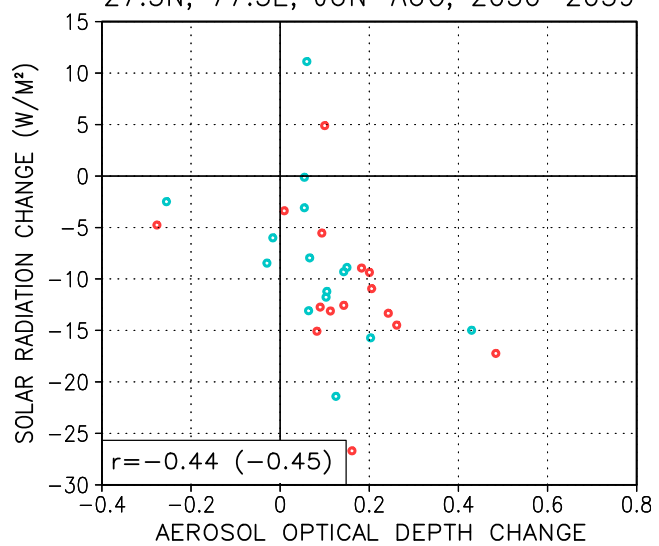

FIG. 6. Scatter diagrams showing the simulated changes (from 1971-2000 to 2030-59) in incident surface solar radiation, in conjunction with changes (top) in cloud attenuation ratio, (middle) atmospheric water vapor content, and (bottom) aerosol optical depth at $550 \mathrm{~nm}$ at $27.5^{\circ} \mathrm{N}, 77.5^{\circ} \mathrm{E}$ for the individual models, with the bivariate distributions depicted for (left) December-February and (right) June-August; model simulations under RCP4.5 are marked by blue circles, and those under RCP8.5 are shown by red circles. The correlation coefficients between the responses in the two variables under RCP8.5 (and in parentheses for RCP4.5) are given in the bottom-left corners of the panels. 

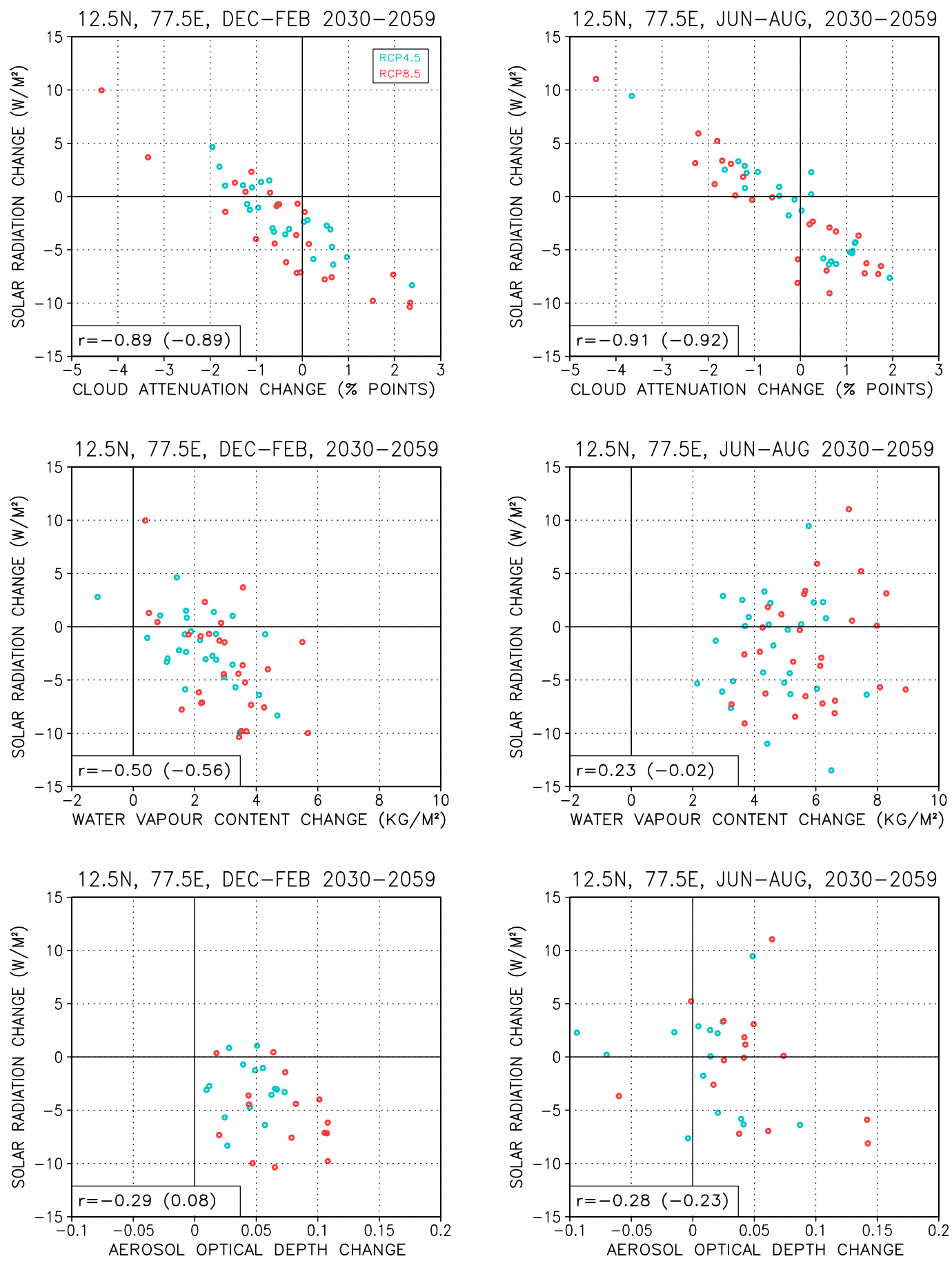

FIG. 7. Scatter diagrams showing the simulated changes in incident surface solar radiation in conjunction with changes in three other variables at $12.5^{\circ} \mathrm{N}, 77.5^{\circ} \mathrm{E}$ for the individual models. For further information, see Fig. 6.

and 7 by scatter diagrams and in Table 3 by correlation coefficients.

In general, the variable that has the highest correlation with intermodel differences in the incident solar radiation response is the cloud attenuation ratio
(Table 3). Changes in incident radiation and cloud attenuation tend to correlate negatively, and at the southern example grid point the correlation is as high as $\sim-0.9$ (Fig. 7). A plausible physical interpretation for this correlation is that increasing (decreasing) cloud 
TABLE 3. Correlation coefficients between projected seasonal changes (from 1971-2000 to 2030-59) in incident surface solar radiation in the various GCMs and corresponding changes in cloud attenuation ratio, atmospheric water vapor content, aerosol optical depth, and clear-sky solar radiation. In addition, correlations of clear-sky radiation changes with changes in water vapor content and aerosol optical depth are given. The correlations have been calculated across the model ensemble separately for two grid points $\left(27.5^{\circ} \mathrm{N}, 77.5^{\circ} \mathrm{E}\right.$ and $12.5^{\circ} \mathrm{N}, 77.5^{\circ} \mathrm{E}$ ) and two greenhouse gas scenarios (RCP4.5 and RCP8.5). Correlations significant at the 5\% level according to a two-tailed $t$ test are boldfaced. (Note that the significance analysis should be considered approximate because the model ensemble is not entirely independent.)

\begin{tabular}{|c|c|c|c|c|c|c|c|c|c|}
\hline & & \multicolumn{4}{|c|}{$\mathrm{RCP} 4.5$} & \multicolumn{4}{|c|}{ RCP8.5 } \\
\hline & & Dec-Feb & Mar-May & Jun-Aug & Sep-Nov & Dec-Feb & Mar-May & Jun-Aug & Sep-Nov \\
\hline \multicolumn{10}{|c|}{$27.5^{\circ} \mathrm{N}, 77.5^{\circ} \mathrm{E}$} \\
\hline Solar radiation & Cloud attenuation & -0.81 & -0.59 & -0.73 & -0.71 & -0.76 & -0.66 & -0.72 & -0.40 \\
\hline Solar radiation & Water vapor content & -0.73 & -0.74 & -0.64 & -0.70 & -0.77 & -0.79 & -0.56 & -0.53 \\
\hline Solar radiation & Aerosol optical depth & -0.56 & -0.47 & -0.45 & -0.71 & -0.46 & -0.58 & -0.44 & -0.62 \\
\hline Solar radiation & Clear-sky radiation & 0.81 & 0.77 & 0.63 & 0.88 & 0.84 & 0.84 & 0.61 & $\mathbf{0 . 8 3}$ \\
\hline Clear-sky radiation & Water vapor content & -0.51 & -0.63 & -0.41 & -0.51 & -0.59 & -0.67 & -0.49 & -0.40 \\
\hline Clear-sky radiation & Aerosol optical depth & -0.95 & -0.95 & -0.97 & -0.95 & -0.95 & -0.95 & -0.98 & -0.94 \\
\hline \multicolumn{10}{|c|}{$12.5^{\circ} \mathrm{N}, 77.5^{\circ} \mathrm{E}$} \\
\hline Solar radiation & Cloud attenuation & -0.89 & -0.84 & -0.92 & -0.92 & -0.89 & -0.67 & -0.91 & -0.81 \\
\hline Solar radiation & Water vapor content & -0.56 & 0.02 & -0.02 & -0.34 & -0.50 & -0.08 & 0.23 & -0.13 \\
\hline Solar radiation & Aerosol optical depth & 0.08 & -0.67 & -0.23 & -0.38 & -0.29 & -0.71 & -0.28 & -0.41 \\
\hline Solar radiation & Clear-sky radiation & 0.60 & 0.82 & 0.32 & 0.62 & 0.63 & 0.70 & 0.26 & 0.55 \\
\hline Clear-sky radiation & Water vapor content & -0.23 & -0.01 & -0.14 & -0.56 & -0.37 & -0.11 & -0.27 & -0.55 \\
\hline Clear-sky radiation & Aerosol optical depth & -0.85 & -0.92 & -0.96 & -0.91 & -0.90 & -0.90 & -0.95 & -0.90 \\
\hline
\end{tabular}

attenuation is an important factor that acts to reduce (enhance) the solar radiation flux reaching the surface. It can be noted, however, that even in many model simulations in which cloud attenuation becomes weaker, the incident solar radiation nevertheless decreases because of decreasing clear-sky radiation (Fig. 6, top panels), which most likely arises from increasing water vapor and/or aerosol content. Especially in the north, simulated changes in incident radiation show statistically significant negative correlations with changes in water vapor content and, in some seasons, with changes in aerosol optical depth (Fig. 6). In the south, by contrast, correlations with the water vapor and aerosol responses are mainly low. This is an indication of the dominant role of changes in cloud forcing in accounting for inter-GCM spread in the solar radiation response. Water vapor and aerosol forcings operate effectively only within the clear portion of the sky, and, because of the longer monsoon season (Lockwood 1974), in the south the modeled (as well as observed) cloudiness is generally larger than in the north. In line with this idea, in the south in summer, the correlation between changes in all-sky and clear-sky radiation is likewise low and does not pass the $5 \%$ significance threshold. Note that while the clear-sky radiation calculations exclude by definition the impact of cloud liquid water and ice, the impact of high water vapor content in cloudy conditions is still taken into consideration.

Furthermore, there is a very strong negative correlation between changes in the clear-sky solar radiation and aerosol optical depth in all seasons (the lowermost rows in Table 3); the more the aerosol loading increases (decreases) in the future, the more the clear-sky solar radiation would weaken (strengthen). The relationship between the clear-sky radiation and column water vapor content responses is weaker and statistically significant mainly in the north. One explanation for this difference may be that the intermodel divergence in the changes of aerosol optical depth is consistently far larger (in relative terms) than the corresponding variability in atmospheric humidity change (Table 2).

The univariate distributions of the quantities depicted in Figs. 6 and 7 indicate that in the north, about $90 \%$ of the present GCMs simulate a reduction in incident solar radiation. In the south, the intermodel agreement is not this strong. Water vapor content will increase in virtually all the model simulations; as stated above, this is a wellknown consequence of global warming. Aerosol optical depth is likewise projected to increase: in winter in all model experiments and in summer in a large majority of them. For the cloud attenuation ratio, by contrast, model projections are quite diverse, there being almost an equal proportion of models projecting an upward and downward trend.

\section{d. Relations between simulated present-day radiation and projected changes}

The scatter diagrams presented in Fig. 8 illustrate the relationship between the modeled present-day temporal means of incident solar radiation and the simulated changes within the GCM ensemble. At both example 

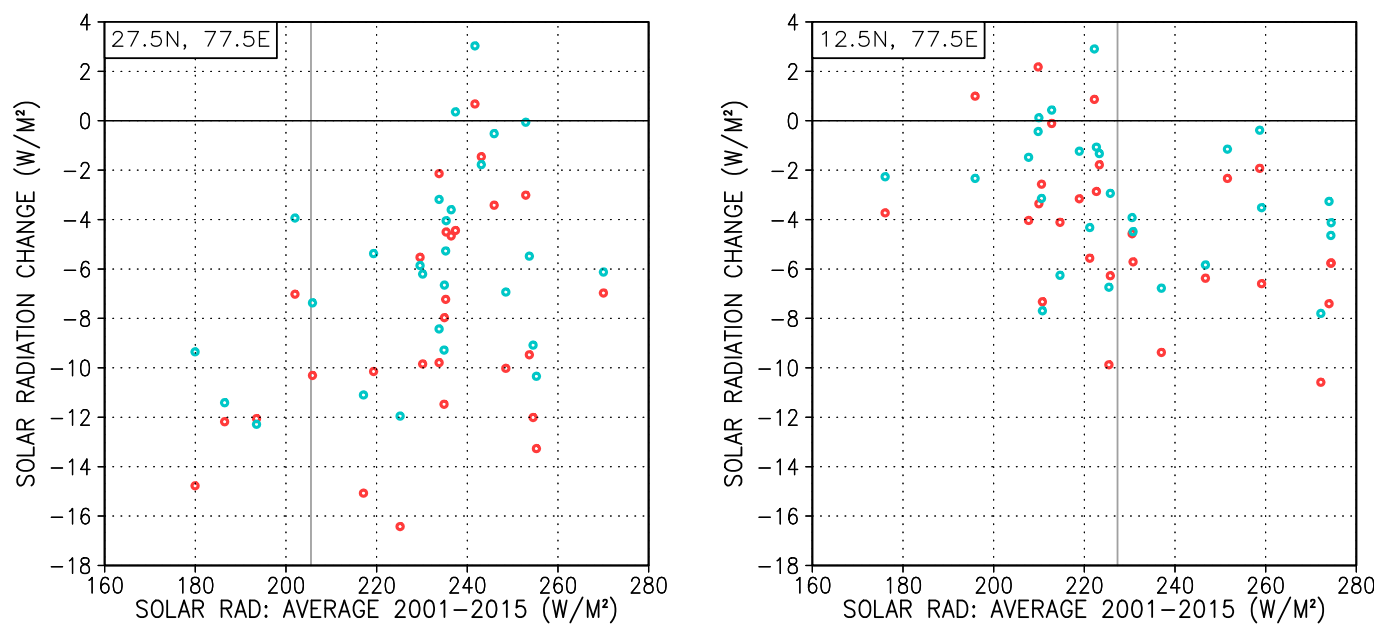

FIG. 8. Annual-mean change in incident surface solar radiation from 1971-2000 to 2030-59 as a function of the simulated temporal mean of the radiation for the period of $2001-15$ for (left) $27.5^{\circ} \mathrm{N}, 77.5^{\circ} \mathrm{E}$ and (right) $12.5^{\circ} \mathrm{N}$, $77.5^{\circ} \mathrm{E}$; simulations are performed with the individual models $\left(\mathrm{W} \mathrm{m}^{-2}\right)$. Model simulations under RCP4.5 are marked by blue circles, and those under RCP8.5 are shown by red symbols. The observational estimate for the timemean radiation, derived from the CERES EBAF surface dataset, is marked by a gray vertical line.

locations, the annual-mean surface radiation modeled for the period 2001-15 diverges substantially among the GCMs, ranging from approximately 180 to $270 \mathrm{~W} \mathrm{~m}^{-2}$. In the northern point, a majority of the models overestimate the time-mean radiation, while in the south, negative and positive biases are approximately equally frequent. This distribution is in concordance with Fig. 1, which likewise revealed positive modeling biases for the north. For the clear-sky radiation (in particular, when disregarding the outlier CNRN-CM5 GCM that produces very small values), the spread among the GCMs is considerably smaller (Fig. 9). This indicates that intermodel differences in historical incident all-sky radiation predominantly stem from the divergent simulations of cloud radiative forcing.

For projected future changes, the variations between the GCM simulations are an order of magnitude smaller than the differences in the present-day simulations. More importantly, the GCMs agree quite well on the sign of the change. Accordingly, despite the large intermodel differences in the simulated present-day radiation climate, the projected decline of incident radiation by midcentury appears to be rather robust.

The bivariate distributions show no discernible dependence between biases in the present-day simulation and the projected changes. A similar conclusion was drawn by Knutti et al. (2010) who likewise found that the ability of a GCM to simulate present-day climate relates quite weakly to the predicted change. Consequently, if the present analysis were founded on a more limited ensemble of GCMs by omitting the models showing low performance in simulating present-day solar radiation, the salient inferences would not be altered materially.
Nevertheless, retaining the full multitude of models enables finding more robust estimates for the intermodel spread of the projection.

\section{Discussion and conclusions}

For the multimodel-mean responses to all three RCP scenarios over different areas of India, the annual-mean incident solar radiation at the surface would diminish by about 0.5 to $4 \%$ during the next decades (by the period 2030-59), relative to the climatology of 1971-2000 (Figs. 2 and 3). The most pronounced reduction is projected for the densely populated areas of northern India. Longerterm projections, by contrast, are strongly dependent on the future evolution of anthropogenic emissions. According to the low-to-medium-emission RCP2.6 and RCP4.5 scenarios, solar radiation would recover during the late twenty-first century close to the level that prevailed in the late twentieth century. Conversely, if the high-emission RCP8.5 scenario is realized, a slow decline is anticipated to continue throughout the century.

During the early twenty-first century, the reduction of incident solar radiation coincides with the amplification of aerosol loading and the increase of water vapor content in the atmosphere. Under RCP2.6 and RCP4.5, aerosol forcing starts to weaken before midcentury while the increase of water vapor content slows down. The combined effect of these two factors corresponds to a gradual recovery of solar radiation during the second half of the century. Conversely, according to RCP8.5, aerosol forcing decreases more slowly than under the other two scenarios and, as a result of the 

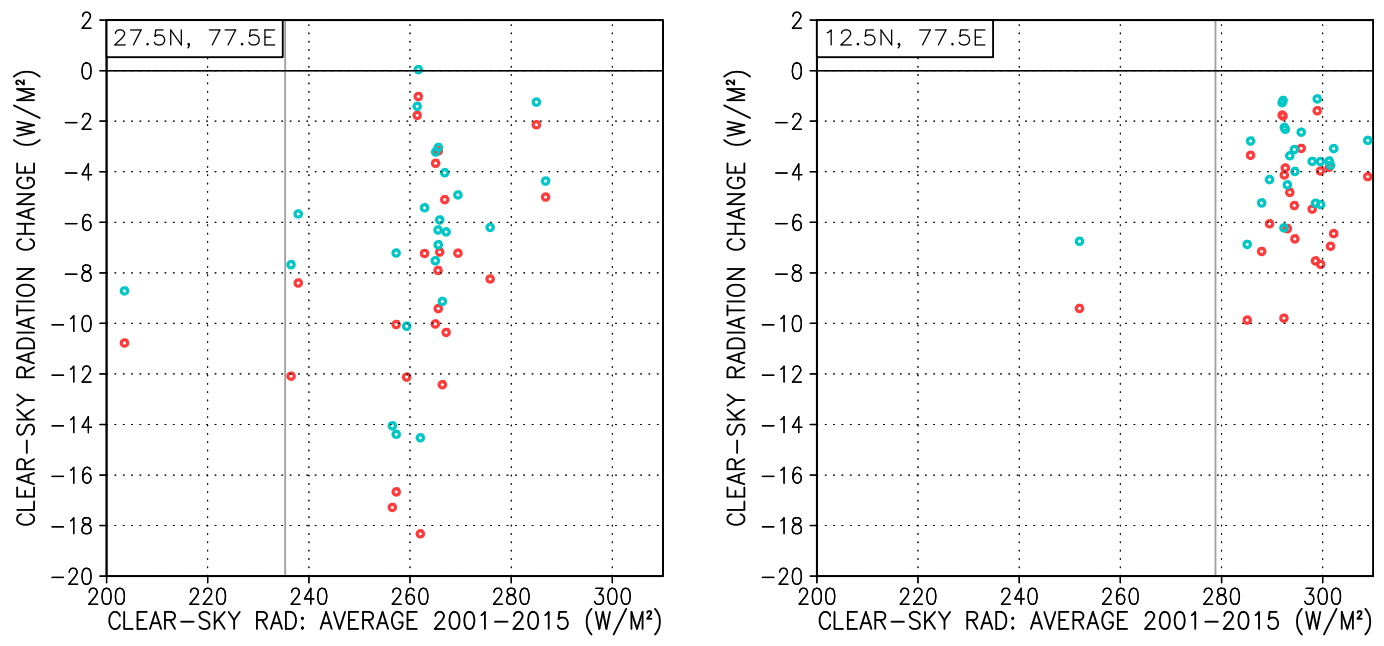

FIG. 9. As in Fig. 8, but for clear-sky radiation.

intense warming of climate, water vapor content further increases substantially. Correspondingly, the negative trend in incident radiation continues.

In the multimodel mean, changes in cloud attenuation are generally minor and do not significantly contribute to changes in incident solar radiation. However, variations among the simulations are substantial. We found that it is the intermodel differences in the cloud attenuation ratio response that correlate most strongly with the modeled changes in surface solar radiation. This suggests that changes in cloudiness and cloud radiative properties are likely to be an important uncertainty factor for the future development of incident surface solar radiation in India.

Although the projected multimodel-mean changes in incident radiation are fairly small, it should be recalled that some individual models simulate far more severe reductions in solar radiation than the $27 \mathrm{GCMs}$ on average, up to $\sim 10 \%$. Conversely, in a few models the incident radiation even increases. The actual uncertainty induced by the modeling differences may even be larger than what is reported in this paper (Figs. 3 and 4; Table 2), since not all of the GCMs analyzed are completely independent; for instance, the 27-GCM ensemble (Table 1) contains 10 double-model versions originating from the same research centers. Moreover, the uncertainty intervals derived for the different quantities are not entirely comparable, since projections for aerosol optical depth were founded on $15 \mathrm{GCMs}$ alone, while data were available from 24-27 GCMs for the other variables. For a sensitivity assessment, we recalculated the incident solar radiation projection from the subensemble of those 15 GCMs that provide data for all the variables. In a qualitative sense, the response was similar to that derived from the full ensemble, but the projected change was somewhat larger. For example, under RCP8.5 the annual multimodel-mean decline of incident radiation in northern India amounted to $4 \%-5 \%$ (cf. to Fig. 2).

The ability of the individual GCMs to reproduce the observation-based time-mean radiation varies remarkably (Fig. 8). This is a factor that may inflict additional uncertainty in the future projections, even though the modeled responses diverge far less than the simulated temporal means. The CMIP5 GCMs likewise have difficulties in reproducing the recent observed trends in incident radiation (Allen et al. 2013). Moreover, the spatial resolution of the GCMs is generally too coarse for resolving finescale geographical details in the incident radiation response, for example, those induced by the spatial distributions of orography and anthropogenic emissions of aerosol precursors. The geographical distribution is further smoothed by averaging over the large ensemble of GCMs. In some previous studies (e.g., Anandhi et al. 2014), solar radiation projections for limited areas have been produced by exploiting spatial downscaling, but such an approach is beyond the scope of the present work. By studying the European area, Bartók et al. (2017) learned that the biases in the current solar radiation are typically even larger in the regional model simulations than in the output of GCMs. Moreover, in short time scales, incident radiation may fluctuate significantly because of the internal variability of the climate system, the temporal evolution thus deviating transiently from the long-term climatological trend.

Future changes in Indian climate are predominantly driven by the global emissions of greenhouse gases and aerosol precursors. Accordingly, it is the evolution of global emissions that likewise largely determines future 
trends in attenuation by atmospheric water vapor and clouds (even though cloudiness may also be influenced by local aerosol forcing). Conversely, aerosol loading over India depends in a large degree on regional emissions originating from the Indian territory and its adjacent areas (Bergin et al. 2017). Thus, while the Indian national environmental policy alone has only a limited opportunity to influence future changes in the forcing due to water vapor and cloudiness, the evolution of aerosol burden is primarily subject to domestic emissions originating from biomass burning, energy sector, industry, and so on.

In formulating the RCP scenarios, the emissions of greenhouse gases and aerosol precursors have both been given as external forcing factors. The projections presented in this paper have been derived directly from the output of the GCM runs forced by the alternative RCP scenarios. Thus, the present projections are constrained by this arbitrary connection between the aerosol and greenhouse gas forcings. Nonetheless, as discussed above, the evolution of the actual regional aerosol forcing does not necessarily match the corresponding RCP scenario. For example, if global emissions followed RCP4.5 but the regional aerosol loading did not decrease as much as hypothesized under this scenario, incident surface solar radiation might fail to recover during the second half of the twenty-first century.

The projected multimodel-mean changes in incident radiation are evidently not substantial enough to critically influence the conditions of solar energy production in India. Other factors, such as the evolution of the consumption of electricity, the costs of solar energy production compared with other energy sources and the vigor of climate change mitigation measures may be far more important. Additional factors that are likely to influence future solar electricity production conditions are the projected warming and soiling of solar panels. Rising temperatures will slightly reduce the electricity output, as the relative efficiency of current photovoltaic cell technologies typically decreases by $0.5 \%$ per $1^{\circ}$ increase in the cell temperature (Radziemska 2003; Krauter et al. 1999). Soiling of the panels by dust and anthropogenic particulate matter has also been found to cause significant reductions in electricity production in India (Bergin et al. 2017). Since both soiling and incident solar radiation depend on the aerosol burden of the atmosphere, they are likely to evolve in a similar manner in the future. As discussed above, this implies that local environmental policy measures thereby have a potential to improve the conditions for solar electricity production.

Acknowledgments. This research was funded jointly by the Academy of Finland (decision 284536) and the
Department of Science and Technology (Contract INT/ Fin/P-14), India. The CMIP5 GCM data were downloaded from the Earth System Grid Federation (ESGF) data archive (http://esgf-node.llnl.gov/search/cmip5). The modeling groups are acknowledged for making their model output available through ESGF. We thank the anonymous reviewers of the manuscript for their comments that helped us to clarify representation.

\section{REFERENCES}

Allen, R. J., J. R. Norris, and M. Wild, 2013: Evaluation of multidecadal variability in CMIP5 surface solar radiation and inferred underestimation of aerosol direct effects over Europe, China, Japan, and India. J. Geophys. Res. Atmos., 118, 63116336, https://doi.org/10.1002/jgrd.50426.

Anandhi, A., V. V. Srinivas, D. Nagesh Kumar, R. S. Nanjundiah, and P. H. Gowda, 2014: Climate change scenarios of surface solar radiation in data sparse regions: A case study in Malaprabha River Basin, India. Climate Res., 59, 259-270, https:// doi.org/10.3354/cr01180.

Bartók, B., and Coauthors, 2017: Projected changes in surface solar radiation in CMIP5 global climate models and in EURO-CORDEX regional climate models for Europe. Climate Dyn., 49, 2665-2683, https://doi.org/10.1007/ s00382-016-3471-2.

Bergin, M. H., C. Ghoroi, D. Dixit, J. J. Schauer, and D. T. Shindell, 2017: Large reductions in solar energy production due to dust and particulate air pollution. Environ. Sci. Technol. Lett., 4, 339-344, https://doi.org/10.1021/acs.estlett.7b00197.

Chou, M.-D., 1990: Parameterizations for the absorption of solar radiation by $\mathrm{O}_{2}$ and $\mathrm{CO}_{2}$ with application to climate studies. J. Climate, 3, 209-217, https://doi.org/10.1175/1520-0442(1990) $003<0209$ :PFTAOS $>2.0 . \mathrm{CO} ; 2$.

Christensen, J. H., and Coauthors, 2013: Climate phenomena and their relevance for future regional climate change. Climate Change 2013: The Physical Science Basis, T. F. Stocker et al., Eds., Cambridge University Press, 1217-1308.

Collins, M., and Coauthors, 2013: Long-term climate change: Projections, commitments and irreversibility. Climate Change 2013: The Physical Science Basis, T. F. Stocker et al., Eds., Cambridge University Press, 1029-1136.

Dee, D. P., and Coauthors, 2011: The ERA-Interim reanalysis: Configuration and performance of the data assimilation system. Quart. J. Roy. Meteor. Soc., 137, 553-597, https://doi.org/10.1002/qj.828.

Delgado, R. C., J. F. de Oliveira Jr., G. Gois, and G. B. Lyra, 2014: Cenários climáticos da radiação solar global baseados no modelo regional HadRM3 para o Estado do Acre (in Portuguese with English abstract). Floresta Ambiente, 21, 417-428, https://doi.org/10.1590/2179-8087.082214.

Dey, S., and L. Di Girolamo, 2010: A climatology of aerosol optical and microphysical properties over the Indian subcontinent from 9 years (2000-2008) of Multiangle Imaging Spectroradiometer (MISR) data. J. Geophys. Res., 115, D15204, https://doi.org/10.1029/2009JD013395.

Flato, G., and Coauthors, 2013: Evaluation of climate models. Climate Change 2013: The Physical Science Basis, T. F. Stocker et al., Eds., Cambridge University Press, 741-866.

Gueymard, C., 2004: The sun's total and spectral irradiance for solar energy applications and solar radiation models. Sol. Energy, 76, 423-453, https://doi.org/10.1016/j.solener.2003.08.039. 
Kato, S., N. G. Loeb, F. G. Rose, D. R. Doelling, D. A. Rutan, T. E. Caldwell, L. Yu, and R. A. Weller, 2013: Surface irradiances consistent with CERES-derived top-of-atmosphere shortwave and longwave irradiances. J. Climate, 26, 2719-2740, https:// doi.org/10.1175/JCLI-D-12-00436.1.

Knutti, R., R. Furrer, C. Tebaldi, J. Cermak, and G. A. Meehl, 2010: Challenges in combining projections from multiple climate models. J. Climate, 23, 2739-2758, https://doi.org/ 10.1175/2009JCLI3361.1.

Krauter, S., R. G. Araújo, S. Schroer, R. Hanitsch, M. J. Salhi, C. Triebel, and R. Lemoine, 1999: Combined photovoltaic and solar thermal systems for facade integration and building insulation. Sol. Energy, 67, 239-248, https://doi.org/10.1016/ S0038-092X(00)00071-2.

Leduc, M., R. Laprise, R. de Elía, and L. Šeparović, 2016: Is institutional democracy a good proxy for model independence? J. Climate, 29, 8301-8316, https://doi.org/10.1175/JCLI-D-15-0761.1.

Lockwood, J. G., 1974: World Climatology: An Environmental Approach. Edward Arnold, $330 \mathrm{pp}$

Loeb, N. G., B. A. Wielicki, D. R. Doelling, G. L. Smith, D. F. Keyes, S. Kato, N. Manalo-Smith, and T. Wong, 2009: Toward optimal closure of the Earth's top-of-atmosphere radiation budget. J. Climate, 22, 748-766, https://doi.org/10.1175/2008JCLI2637.1.

Lorenz, D. J., and E. T. DeWeaver, 2007: The response of the extratropical hydrological cycle to global warming. J. Climate, 20, 3470-3484, https://doi.org/10.1175/JCLI4192.1.

Mani, A., and S. Rangarajan, 1982: Solar Radiation over India. Allied Publishers, 647 pp.

Meydbray, J., K. Emery, and S. Kurtz, 2012: Pyranometers, reference cells: The difference. PV Mag., 4, 108-110.

Ministry of New and Renewable Energy, 2015: Scaling up of grid connected solar power projects from $20,000 \mathrm{MW}$ by the year 2021-22 to 100,000 MW by the year 2021-22 under National Solar Mission. Government of India Tech. Rep. 30/80(2014-15/NSM), https://mnre.gov.in/sites/default/files/schemes/100000MWGrid-Connected-Solar-Power-Projects-by-2021-22.pdf.

Padma Kumari, B., A. L. Londhe, S. Daniel, and D. B. Jadhav, 2007: Observational evidence of solar dimming: Offsetting surface warming over India. Geophys. Res. Lett., 34, L21810, https://doi.org/10.1029/2007GL031133.
Radziemska, E., 2003: The effect of temperature on the power drop in crystalline silicon solar cells. Renewable Energy, 28, 1-12, https://doi.org/10.1016/S0960-1481(02)00015-0.

Ramachandra, T. V., R. Jain, and G. Krishnadas, 2011: Hotspots of solar potential in India. Renewable Sustainable Energy Rev., 15, 3178-3186, https://doi.org/10.1016/j.rser.2011.04.007.

Ruosteenoja, K., and P. Räisänen, 2013: Seasonal changes in solar radiation and relative humidity in Europe in response to global warming. J. Climate, 26, 2467-2481, https://doi.org/ 10.1175/JCLI-D-12-00007.1.

Saenz, G. A., and H.-P. Huang, 2015: Trends in downward solar radiation at the surface over North America from climate model projections and implications for solar energy. Adv. Meteor., 2015, 483679, https://doi.org/10.1155/ 2015/483679.

Soni, V. K., G. Pandithurai, and D. S. Pai, 2012: Evaluation of longterm changes of solar radiation in India. Int. J. Climatol., 32, 540-551, https://doi.org/10.1002/joc.2294.

,-- , and -2016 : Is there a transition of solar radiation from dimming to brightening over India? Atmos. Res., 169, 209-224, https://doi.org/10.1016/j.atmosres.2015.10.010.

Taylor, K. E., R. J. Stouffer, and G. A. Meehl, 2012: An overview of CMIP5 and the experiment design. Bull. Amer. Meteor. Soc., 93, 485-498, https://doi.org/10.1175/BAMS-D-11-00094.1.

van Vuuren, D. P., and Coauthors, 2011: The representative concentration pathways: An overview. Climatic Change, 109, 531, https://doi.org/10.1007/s10584-011-0148-z.

Weigel, A. P., R. Knutti, M. A. Liniger, and C. Appenzeller, 2010: Risks of model weighting in multimodel climate projections. J. Climate, 23, 4175-4191, https://doi.org/10.1175/2010JCLI3594.1.

Wild, M., 2012: Enlightening global dimming and brightening. Bull. Amer. Meteor. Soc., 93, 27-37, https://doi.org/10.1175/ BAMS-D-11-00074.1.

—, D. Folini, F. Henschel, N. Fischer, and B. Müller, 2015: Projections of long-term changes in solar radiation based on CMIP5 climate models and their influence on energy yields of photovoltaic systems. Sol. Energy, 116, 12-24, https://doi.org/ 10.1016/j.solener.2015.03.039.

WMO, 1989: Calculation of monthly and annual 30-year standard normals. WCDP-10, WMO-TD/341, 11 pp. 